\title{
FACILITATING MULTIPLE INTELLIGENCES THROUGH MULTIMODAL LEARNING ANALYTICS
}

\author{
Ayesha PeRVeen \\ Department of English \\ Virtual University \\ Lahore, Pakistan
}

\section{ABSTRACT}

This paper develops a theoretical framework for employing learning analytics in online education to trace multiple learning variations of online students by considering their potential of being multiple intelligences based on Howard Gardner's 1983 theory of multiple intelligences. The study first emphasizes the need to facilitate students as multiple intelligences by online education systems and then suggests a framework of the advanced form of learning analytics i.e., multimodal learning analytics for tracing and facilitating multiple intelligences while they are engaged in online ubiquitous learning. As multimodal learning analytics is still an evolving area, it poses many challenges for technologists, educationists as well as organizational managers. Learning analytics make machines meet humans, therefore, the educationists with an expertise in learning theories can help technologists devise latest technological methods for multimodal learning analytics and organizational managers can implement them for the improvement of online education. Therefore, a careful instructional design based on a deep understanding of students' learning abilities, is required to develop teaching plans and technological possibilities for monitoring students' learning paths. This is how learning analytics can help design an adaptive instructional design based on a quick analysis of the data gathered. Based on that analysis, the academicians can critically reflect upon the quick or delayed implementation of the existing instructional design based on students' cognitive abilities or even about the single or double loop learning design. The researcher concludes that the online education is multimodal in nature, has the capacity to endorse multiliteracies and, therefore, multiple intelligences can be tracked and facilitated through multimodal learning analytics in an online mode. However, online teachers' training both in technological implementations and adapting educational theories to online education is necessary to achieve this ideal.

Keywords: Learning analytics, multimodal learning analytics, multiple intelligences, online learning, instructional design, double loop learning.

\section{INTRODUCTION}

Although the use of analytics is not new in formal education (McNeill, 2012), learning analytics (LA) is a buzzword in online education now a days. In this regard, the most popular method of collecting data in traditional educational mode has been student surveys, but latest innovations in technology has facilitated data collection about students through the help of learning analytics (Klemencic \& Chirikov, 2015). In spite of being a popular term, the definition of learning analytics (henceforward LA) may seem confusing because of the use of similar terms like 'academic analytics'. Long and Siemens (2011) differentiate 'academic analytics' from 'learning analytics' by limiting LA only to the learning processes of students and consider organizational processes a part of 'academic analytics'. Buckingham Shum (2012) further divides LA into three types: macro, meso and micro. Macro level of LA, according to him, refers to the sharing of analytics across institutions, meso is more concerned with business intelligence at 
individual institutional level and micro refers to the tracking and interpretation of individual learners' data. In spite of the meagre differences in the definition, the connotation of the term remains the same i.e., tracking the digital footprints of the students (Long \& Siemens, 2011) by collecting their activity logs for the overall improvement of the system.

New technological developments in analytic tools and applications have led to innovative visions about the maximum utilization of big data (MacNeill, Campbell \& Hawksey, 2014). However, actionable insight is required for the useful analysis of big data (Cooper, 2012) from students' learning perspective. In this regard, Campbell and Oblinger (2007) present a five-step model of LA: capture, report, predict, act and refine. However, Clow (2012) recommends shortening of the LA circle by providing quick feedback to students. Overall, the main goal is to support learning by devising educational datasets, the analysis of which can lead to a better instructional design (Lockyer, Heathcote, \& Dawson, 2013). The data collected should be quickly analyzed for predicting learners' needs as well as the shortcomings of the instructional design and any other aspects of the system. The quick analysis can help modify the system/instructional design, challenge the single loop learning and inspire for double loop learning to meet learners' needs for a better academic performance and achieve improved learning outcomes. Overall, the term LA refers to measuring and evaluating of the data encompassing students learning progress inside an online system like a Learning Management System (LMS) or Course Management System (CMS). The analytics can help in several ways: predict students' performance, analyze the causes of low or high performance, provide food for thought to teachers and administrators of online system about their success or system's drawbacks and, above all, help and guide towards developing an improved instructional design focusing on better achievement of learning outcomes. For this, currently the tracking functionality of LMS/CMS is limited (Hijran \& Carlos, 2006) and better reports should be provided to the teachers for a quick and facile analysis. In short, LA is beneficial on all institutional levels as it can: (1) support students through their needs analysis and addressing those needs; (2) develop a metacognition amongst students to learn through understanding their own mistakes; (3) support teachers by providing students' progress figures for guiding them accordingly; (4) help universities to improve curriculum based on the analytics and (5) support the administration in decision making about taking measures for image-building through marketing (Powell \& MacNeill, 2012).

\section{Learning Analytics as a Learning Facilitator}

Learning analytics as an emerging new disciple has much potential to broaden its scope by focusing on the complexity of learning process and devising a mechanism to map that complexity in measurable data (Siemens, 2013). If LA achieves the level of determining students' personal learning needs, thereby predicting ways of better performance, it can support multiliteracies i.e., multiple pedagogic and learning strategies. Therefore, existing level of LA has ample room for inculcating novel insights into teaching and learning endeavors (Siemens, 2013). Data analysis poses enormous challenges and only experienced online teachers/academicians with sound knowledge of educational theories can be good at analysis. Therefore, LA needs the support of established learning theories (Clow, 2012) to devise effective instructional strategies. Initially overawed by the promising aspects of technology for LA, researchers are now paying heed to the importance of learning theories for any educational system. Therefore, new researches emphasize that LA should be concerned with learning primarily and technology should act as a facilitator rather than overshadowing learning process (Gasevic, Dawson, \& Siemens, 2015). In this regard, this study's focus is to explore the use of LA for addressing learning variations and abilities of online students as their interest in learning can be stimulated based on their dispositions and attitudes (Shum \& Crick, 2012).

Learning analytics can determine the future of education through improvising an innovative design for online classrooms through data monitoring. LA can be used to improve educational processes in higher education through the analysis of students' performance, which can be utilized to devise an improved instructional design to support 
weaker students as well as provide them timely feedback to motivate them to struggle for better grades (Siemens \& Long, 2011). However, there still is room for ample research to devise appropriate models and methods for LA (Siemens \& Baker, 2012). Big data can be of great help in understanding and improving the science of learning (Baker \& Inventado, 2014). Based on analytics, new software can be developed to provide feedback to students e.g., 'signals' which was introduced at Purdue University. 'Signals' assigns separate colors to students as indicators of their performance, each color signifying whether they are faring well or are in danger (Arnold \& Pistilli, 2012). However, a lot of creative input is required to render this sort of output. The process may involve critical reflection for appropriate action. For example, as generally the teachers provide feedback after analyzing students' performance by the end of the semester (Lias \& Elias, 2011), to provide time to time feedback to students after carefully analyzing their step by step performance and modifying instructional design within a semester can be extremely demanding. Although data is generally quantitatively analyzed like page access, time on tasks, successful submissions, numbers, grades etc., qualitative analysis like content analysis should be given consideration too. Apart from simple monitoring of the time involved in reading online material or interaction patterns in discussion forums (Lias \& Elias, 2012), LA should pay head to discourse analysis as well (De Liddo, Shum, Quinto, Bachler, \& Cannavacciuolo, 2011). The analysis of discourse, semantics and sentiments in discussions can help design predictive models through an intelligent curriculum. Research should continue for a perfect blend of technology, educational theory and reflective practice (Siemens, 2012). For this the technocrats, educationists and researchers will have to look beyond simple LA to multimodal learning analytics (Blikstein, 2013). As online learning's scope is beyond LMS/CMS because individual study can take place at home or at any other place and group interactions exist in any virtual space, to capture all that spread-out data for evaluation is an arduous task.

Multimodal Learning Analytics (MMLA)

With the advancements in LA tools, interactive learning environments for a large number of participants can be easily analyzed (Worsley, \& Blikstein, 2014). Such open-ended or even informal interactive learning environments can be encompassed through multimodal learning analytics (henceforward MMLA). MMLA is currently the most advanced and promising form of LA as it offers a possibility of tracking natural ways of learning and communication patterns during situated individual or group learning activities for analysis. It refers to exploiting all possible sources of information (gestures, speech, movement, writing, online logs, etc.) for a better understanding of the learning process both in online and real-time settings, be it distributed or centralized. It has the potential to help educationists understand students' learning paths and cognitive working even in complex and open ended learning environments (Bilkstein \& Worsely, 2016). However, greater the promise, greater the challenge. How to transform the theoretical underpinnings into practical implementation by fusing multimodal forms of data like voice analysis, gesture analysis, eye movements, students' physical movements whether in front of a computer, in a classroom or group learning environment, calls for analyzing complex learning environments and may need the most advanced forms of technological innovations. Going beyond text and discourse analysis, biosensing, image analysis and head sensors can help capture gestures, movements and cognitive processing over an extended period of time leading to intelligent formative and summative assessments based on multiple learning abilities and styles. This can also help assess certain disabilities in students' learning and lead to inclusive education. With the help of new data mining technologies and new sensing techniques, MMLA can facilitate capturing and analyzing of multiple activities' data including the minutest activities of the students as well as their diverse socialization patterns (Bilkstein \& Worsely, 2016). More researches should be conducted on the use of biosensing, signal and image-processing, text-mining, and machine learning to explore MMLA's potential and future possibilities.

MMLA can be easily operational if the learning process takes place in front of a computer or supporting digital devices (Bilkstein, 2013). Thus, it can foster new vistas of evaluating students' natural learning abilities as it would take into consideration the challenging 
task of systematically monitoring informal or open-ended learning environments (Worsley, 2012) and can lead to the understanding of new possibilities and potential of online learners' support. How students' learning should remain the core area of LA with an aim of improving instructional design by assessing the digital support possibilities is the core aim of MMLA (Morency, Oviatt, Scherer, Weibel, \& Worsley, 2013). Healion et al., (2017) in their study "Tracing physical movement during practice-based learning through Multimodal Learning Analytics" conclude that MMLA facilitates in understanding about the learning process of a small group while working collaboratively through tracing their physical movements but more researches are required for tracing its implications for larger groups. Therefore, there is a dire need to develop more comprehensive theories for technology supported pedagogy based on the challenges arising out of current practices. The learning diversification of larger groups of students requires special attention in this regard.

\section{Multiple Intelligences Theory}

This study highlights the need to focus on students' learning variations before reflecting upon improving existing instructional designs. In online education this can be achieved through the help of LA to provide support to different students based on their variations of learning abilities. To achieve this, LA should be more comprehensive by including human behavior/psychology and innate capabilities/tendency of learning going beyond mere technological mapping of a student's log ins and log outs. The weaknesses of the students should be judged by determining whether the students are/ are not comfortable with a set pattern of instructional design (which is the case with most of the online programs including MOOCs). This makes us consider Howard Gardner's theory of multiple intelligences presented in his seminal work Frames of Mind in 1983. The theory of multiple intelligences challenges the previously dominant IQ theory, which considered linguistic and logical mathematical abilities as the only sources of intelligence. Gardner classifies intelligence into eight types: linguistic, logical-mathematical, spatial, kinesthetic, musical, interpersonal, intrapersonal, and the naturalist. These intelligences can vary in degree in each individual, therefore, no individual should be judged based on one particular intelligence as one intelligence may be dominant in one individual and a different one in others while more than one are usually present simultaneously. The characteristics of all these intelligences are discussed below:

Linguistic Intelligence refers to the capability of being good at word use. Learners with linguistic intelligence can make the best use of words whether oral or written. They can have good auditory skills to segment sounds and even visualize words through sensory perceptions. They can be good at reading and writing including creative writing, and games including words related activities. The capacity to use words effectively ranges from phonology to syntax, and semantics to pragmatics with a flare in the use of rhetoric, mnemonics, textual interpretations and even metalanguage (Armstrong, 2009). This type of intelligences have a high capacity not only for learning many languages, but can also manipulate languages for their purpose as well as turn out to be writers and poets (Smith, 2002).

Logical-Mathematical Intelligence refers to the ability of logical reasoning as well as calculation ability by exploring patterns and their relationships. Students with logicalmathematical intelligence can easily experiment with cause-effect relationships, categorization, classification, inference, generalizations, calculations and hypothesis testing (Armstrong, 2009). Scientists and mathematicians generally have an abundance of this intelligence (Smith, 2002).

Visual-Spatial Intelligence has the capability to understand patterns of space (Smith, 2002). Architects and sailors are this type of intelligence as they are environment sensitive with the potential to think in terms of physical space. Visual Spatial intelligence develops the capability to be good at jigsaw puzzles, drawing charts, graphs, illustrations, photographs and reading maps. Such illustrations and drawings as well as visual and physical imagery can act as inspiring teachers for them. As, they can accurately perceive 
the world due to their sensitivity to visual spatial aspects, 3-D modeling, videos, videoconferencing, television, multimedia and texts with pictures/charts/graphs can be best tools for them to trigger their creativity. Due to the ability to orient themselves to any spatial matrix, they can also represent such matrix in graphical representations by creating relationships between color, line, form, shape and space (Armstrong, 2009).

Musical Intelligence is sensitive to rhythm and sound i.e., pitch, melody, timbre and tone. Learners with this intelligence can perceive and transform, discriminate between and express in musical forms (Armstrong, 2009). They are sensitive enough to trace rhythm in all sounds around and therefore, love music, be it nature's manifestation or human creation. As students, background music can really facilitate the process of learning for them. Making the art of teaching rhythmic by using appropriate background music, turning lessons into lyrics, speaking rhythmically can trigger them to better, quick and creative learning. Musical instruments, radio, TV, stereo, CD-ROM and multimedia are the tools that can be used for such intelligence for better learning.

Kinesthetic Intelligence is good at making the most out of bodily movements because of a keen sense of body awareness. Such intelligence learns best from the rhythm of the body as in dance or by practical tasks performed as by a surgeon or an athlete. Either a part or the whole body is used for the expression of cognition or emotions (Armstrong, 2009). A good use of mental abilities to coordinate and control and express body movements as athletes or performance artists do, is required (Smith, 2002). Body language also becomes a major source of expression. Students with kinesthetic intelligence quickly learn through physical activity, hands-on learning and role-playing.

Intrapersonal Intelligence is all about understanding oneself deeply (Smith, 2002). Students with this intelligence act adaptively based on their self-knowledge to realize their interests and goals. As they have a clear understanding of themselves and their inner moods, they can discipline themselves as well as maintain self-esteem through selfunderstanding (Armstrong, 2009). Such students are generally introverted and avoid socialization because too much human interaction may distract them. This is because they are more in dialogue with their inner-self which becomes a pathway for attaining wisdom through intuition. They learn best through introspection and studying alone.

Interpersonal Intelligence has the ability to understand people's desires and motivations, and based on that, is able to fare well with them. This intelligence is good at human interaction (Smith, 2002) and learns better through interaction. This ability leads to sensing people's feelings, moods, intentions and even motivations by observing their facial expressions, gestures and analyzing voice tones. Therefore, students with interpersonal intelligence win lot of friends because of empathy for others. Moreover, they have the ability to inspire others to follow their desired line of action (Armstrong, 2009). Such students fare well in interaction with class fellows as well as teachers and learn best through group activities, seminars, and class discussions.

Naturalist Intelligence finds natural phenomena inspiring, be they species of flora and fauna - or anything in the environment happening naturally. Students with this type of intelligence are good at categorizing natural as well as scientific inventions. Taxonomies of natural species as well a careful sifting of new technologies like automobiles or computers can be better understood and even described by them (Armstrong, 2009).

Howard Gardner produced further critique after evaluating criticism on his work that intelligence is not a style and several intelligences may work together in an individual simultaneously (Gardner, 2001). While applying this theory to online education's academic technoculture (inclusive of open and formal online education) the focus is to celebrate students' differences in learning by providing them a learning atmosphere that enhances their skills in their peculiar manner rather than undermining their capabilities by thrusting upon them any particular way of learning/single loop learning. This is all the 
more important in online education because the student-teacher interaction time is lesser and different in nature in comparison to the traditional face-to-face classroom, personal learning environment is much more dominant and individual focus on students is almost nonexistent.

Based on this perspective, the paper explores the following research questions:

RQ 1:Can online education easily facilitate multiple intelligences by addressing their diversified needs?

RQ 2:Can multiple intelligences' learning styles be explored and facilitated through the use of advanced forms of learning analytics in online environments?

\section{METHODOLOGY}

The study develops a theoretical framework which first establishes online education's potential to facilitate multiple intelligences and then traces the possibility of tracking and cultivating multiple intelligences through the use of MMLA.

\section{DISCUSSION}

\section{Multiple Intelligences and Online Education}

Multiple intelligence theory can be considered a form of inclusive pedagogy because of its potential to encompass students' learning diversity (Barrington, 2004). This is even more significant for online education because online education caters to students' diversity in geographical, contextual and learning styles. For online education, Multiple Intelligence (henceforward MI) consideration is a reflective way of bridging gaps between the institutional set up and students' needs. As each intelligence has certain peculiar characteristics, to facilitate those individual traits should be a consideration in lesson planning to enable students best learn through the way they utilizes their strengths (Nolen, 2003) in the best possible way. MI theory incorporation can provide a quality online educational experience (Riha \&Robles-Pina, 2009). Riha and Robles-Pina (2009) in their article "The Influence of Multiple Intelligence Theory on Web Based Learning" take up MI theory as a topic of investigation with reference to web-based learning while they maintain that very few studies have been conducted to explore the relationship between MI and online education. MI theory can be much more useful for online learning in comparison to traditional or blended learning because in traditional education although the teacher has certain in person contact hours with students, $s /$ he has to explore types of intelligence individually by investing a lot of time and address them by a carefully revised lesson plan. Online education, on the other hand, is facilitated by tools that, if used effectively, can easily explore and address multiple intelligences' needs. This study does not aim at establishing the usefulness of considering MI for education, rather MI is preconceived as beneficial based on the results of researches like Riha and Robles-Pina's. The next step is to explore the utilization of MI theory in online education by tracking the students' naturalist bent towards learning. This exploration can help towards an adaptive online educational design to support a variety of learning temperaments. In this regard, the table given below proposes best suitable aspects in an online instructional design for a particular intelligence to facilitate best possible learning according to their natural abilities. 
Table 1. Multiple intelligences and online education

\begin{tabular}{|c|c|c|}
\hline Multiple Intelligence & Key Traits & Online Instructional Design \\
\hline Verbal & $\begin{array}{l}\text { learning through } \\
\text { words/language: } \\
\text { (written \& sound) }\end{array}$ & $\begin{array}{ll}\text { - } & \text { synchronous/asynchronous } \\
\text { discussion boards/wikis for collaborative } \\
\text { construction of knowledge } \\
\text { - } \\
\text { better at listening lectures than watching } \\
\text { videos } \\
\text { - } \text { better at chat } \\
\text { - } \text { quizzes/assignments } \\
\text { - good and } X \text { MOOCs } \\
\text { good atoring open learning resources }\end{array}$ \\
\hline Logical Mathematical & $\begin{array}{l}\text { capacity of problem solving } \\
\text { through logical and numerical } \\
\text { patterns }\end{array}$ & $\begin{array}{l}\text { a/synchronous } \\
\text { - } \quad \begin{array}{l}\text { process based instructional design } \\
\text { has the ability to devise patterns even for } \\
\text { distributed learning/personal learning } \\
\text { environments through organized mind } \\
\text { mapping } \\
\text { both } \mathrm{C} / \mathrm{X} \text { MOOCs }\end{array} \\
\end{array}$ \\
\hline Spatial Visual & $\begin{array}{l}\text { capacity to visualize concepts } \\
\text { both accurately and } \\
\text { abstractly } \\
\text { explores virtual } \\
\text { space through its } \\
\text { visual effects }\end{array}$ & $\begin{array}{l}\text { TV/CDs/ videos } \\
\text { better at watching videos than audio } \\
\text { courses } \\
\text { a carefully designed set of instructional } \\
\text { design to appeal visually be it LMS, wikis, } \\
\text { websites, video lectures } \\
\text { good at virtual space, therefore both at X/C } \\
\text { MOOCs as well as at exploring open } \\
\text { learning resources but at visual aspects } \\
\text { only }\end{array}$ \\
\hline Kinesthetic & $\begin{array}{l}\text { body movements } \\
\text { would feel misfit in } \\
\text { online world because } \\
\text { of lack of movement }\end{array}$ & $\begin{array}{l}\text { - } \begin{array}{l}\text { may learn through games as they express } \\
\text { bodily kinesthetic experience that online } \\
\text { learning fails to provide otherwise } \\
\text { may often go to study at campus and feel } \\
\text { better at blended learning } \\
\text { good at typing } \\
\text { more research required to cater this MI in } \\
\text { online education } \\
\text { presentations can be sent in asynchronous } \\
\text { mode or conducted via synchronous }\end{array} \\
\text { sessions } \\
\text { experiential and situated learning can help } \\
\text { - } \quad \begin{array}{l}\text { More of a community of practice } \\
\text { Simulation software can help }\end{array}\end{array}$ \\
\hline Musical & $\begin{array}{l}\text { learning through music, } \\
\text { rhythm }\end{array}$ & $\begin{array}{ll} & \text { a/synchronous } \\
\text { - } & \text { should be taught through audio clips and } \\
\text { use of songs } \\
\text { virtual worlds should use background music } \\
\text { for such students } \\
\text { - teaching through music } \\
\text { any web-based learning that involves audio } \\
\text { and music, esp. social media }\end{array}$ \\
\hline Interpersonal & $\begin{array}{l}\text { learning through interaction, } \\
\text { group work and } \\
\text { communication }\end{array}$ & $\begin{array}{l}\text { - learns through blogs/ wikis social media } \\
\text { good and confident at interaction with } \\
\text { teachers/mediators through } \\
\text { emails/discussion boards/calls } \\
\text { better at C MOOCs/social media }\end{array}$ \\
\hline Intrapersonal & learning through introversion & $\begin{array}{ll} & \text { asynchronous } \\
\cdot & \text { me and my computer type } \\
\cdot & \text { unique personal learning environment } \\
\text { - } & \text { less interactive, more reflective } \\
\text { - } & \text { better at xmooc }\end{array}$ \\
\hline Naturalist & $\begin{array}{l}\text { learning through nature } \\
\text { contact and observation, } \\
\text { plays with categories }\end{array}$ & $\begin{array}{l}\text { - the urban side would be good at computers } \\
\text { and all related paraphernalia } \\
\text { can learn well through intelligent tutoring } \\
\text { system (ITS) }\end{array}$ \\
\hline
\end{tabular}


Online learning can be a kaleidoscope of possibilities to enable students acquire best possible knowledge by using unexplored intelligences, which can lead to new and creative ways of knowledge construction (Medeiros Vieira, Ferasso, \& Schroeder, 2014). Medeiros Viera et al., in their article "Connecting Multiple Intelligences through Open and Distance Learning: Going towards a Collective Intelligence" (2014) consider online learning a revolution in the traditional pedagogical models by meeting the needs of multiple intelligences. Online education has the potential to maximize learning by incorporating latest technologies leading to refined levels of analyses. Interconnection of multiple intelligences and online education will result in moving beyond ordinary levels of education (Medeiros Vieira, Ferasso, \& Schroeder, 2014). Gardner (2011) himself considers new technologies capable of endorsing multiple intelligences as the systems can modify pedagogical design based on the ratio of previous success or failure rates.

As MI theory reaches beyond traditional intelligence theories, there is a need to design an instructional framework accommodating all intelligences. If LA is aimed at improving instructional design, they should be able to record students' progress based on the variety of all types of learning intelligences and thereby analyze the data to devise assessment activities and a revised intelligent curriculum inclusive of all intelligences. Moreover, based on the visual version of data analytics a metacognition should be developed in students not only to make themselves aware of their learning paths and progress but also to develop the courage of taking risks of committing mistakes for learning. This will enable them to be self-reliant/self-sufficient in their personal learning environments and to own their educational progress. Multiple intelligences must be cultivated rather than ignored and discouraged. This is only possible through multimodal learning analytics.

\section{Multiple Intelligences and Multimodal Learning Analytics}

Although tracking students' academic progress is increasingly becoming common in online education through the use of LA, tracing multiple intelligences can be challenging during their evolution and progress in a particular course learning experience. Something challenging, however, is not impossible. MMLA can help measure multiple intelligences but for that not only new technological advancements are required but also pilot studies should be conducted in online institutions or by MOOCs administrators about the effectiveness of certain tools to measure multimodal data. Munoz-Cristobal et al., (2017) emphasize upon teachers' awareness about the learning processes of their students and allude to the difficulty to achieve this target especially in ubiquitous learning environments because of the heterogeneity of context, infrastructure and facilities availability. Researchers have talked about the availability of various low-cost multimodal sensors software kits which can provide an opportunity to design and create collaborative, multimodal learning experiences that engage multiple intelligences. There have been developments in multimodal learning analytics but they are still underexplored like gesture sensing, wearable bio sensors (e.g., that permit measurements of skin conductivity, heartbeat, and electroencephalography), head trackers, infrared imaging, depth imaging and eye tracking (Bilkstein, 2013, Bilkstein \& Worsely, 2016). Their use needs to be explored and experimented further for capturing multiple intelligences' learning paths. The following table presents the type of MMLA required to track each intelligence's learning paths. 
Table 2. Multiple Intelligences and Multimodal Learning analytics

\begin{tabular}{|c|c|c|}
\hline Multiple Intelligence & Key Traits & Multimodal Learning Analytics \\
\hline Verbal & $\begin{array}{l}\text { Learning through } \\
\text { words/language: } \\
\text { (written/sound) }\end{array}$ & text/speech/content/discourse analysis \\
\hline Logical Mathematical & $\begin{array}{l}\text { capacity of problem solving } \\
\text { through logical and numerical } \\
\text { patterns }\end{array}$ & $\begin{array}{l}\text { text/ attempted questions } \\
\text { analysis/problem solving analysis/ } \\
\text { pattern analysis, } \\
\text { head sensors may be required for } \\
\text { cognitive mapping }\end{array}$ \\
\hline Spatial Visual & $\begin{array}{l}\text { capacity to visualize concepts } \\
\text { both accurately and abstractly }\end{array}$ & $\begin{array}{l}\text { cognitive mapping through head } \\
\text { sensors, } \\
\text { eye movement to be captured through } \\
\text { eye sensors }\end{array}$ \\
\hline Kinesthetic & body movements & $\begin{array}{l}\text { visual analytics of postures \& gestures } \\
\text { movements / may need a class } \\
\text { coverage/writing through digital pen, } \\
\text { segmentation and transcription required }\end{array}$ \\
\hline Musical & learning through music, rhythm & sound analytics \\
\hline Interpersonal & $\begin{array}{l}\text { learning through interaction, } \\
\text { group work and communication }\end{array}$ & $\begin{array}{l}\text { social media analytics, class/group } \\
\text { monitoring, visual/sound and discourse } \\
\text { analytics }\end{array}$ \\
\hline Intrapersonal & learning through introversion & $\begin{array}{l}\text { cognitive mapping through /mind/head } \\
\text { sensors, disposition analytics, sentiment } \\
\text { analysis }\end{array}$ \\
\hline Naturalist & $\begin{array}{l}\text { learning through nature contact } \\
\text { and observation, and playing } \\
\text { with categories }\end{array}$ & Visual analytics \\
\hline
\end{tabular}

Mapping multiple intelligences is not a difficult task as already many researchers have proposed ways to use MMLA. For example, in their article "Towards the Development of Multimodal Action Based Assessment" Worsley and Bilkstein (2013) propose techniques to segment and analyze gestures. Disposition analytics can focus on the analysis of motivation, experience, and intelligence in response to learning opportunities. New tools like GRAPPLE and GUIS (Visualization Infrastructure Service) facilitate virtual as well as personal learning environments analytics to use data for metacognitive reflections (Mazzola \& Mazz, 2011). Furguson also supports the argument that learning analytics have developed to the extent that now, move beyond LMS, they can capture date of PLES (Personal Learning Environments) too. However, for that more challenging combinations of datasets including mobile biometric and mood data like confidence, enjoyment, satisfaction would be required. Ochoa et al., in their article "Expertise Estimation Based on Simple Multimodal Features" (Ochoa, Chiluiza, Mendez, Luzardo, Guaman \& Castells, 2013) talk about capturing videos of students' individual and group work, movements to determine most active students, measuring distance from center table through head tracking, audio processing through segmentation leading to transcription, digital pen movements and shapes drawn recognition. Already much advancement has taken place in speech recognition, discourse analysis and social networking analysis (Shum \& Furguson, 2012). Therefore, it really is not difficult to use MMLA to explore, support and cultivate 
multiple intelligences. MMLA, if applied to trace multiple intelligences can help researchers and educationists in the following ways:

$>$ In the beginning of the semester, the students can be guided whether they have chosen the right combination of subjects as a field of study.

$>$ During the course of study, the student can be given clues which domain of knowledge within a particular field $s /$ he can perform best at.

$>$ Asynchronous/synchronous/blended modes can be recommended based on dominant intelligences.

$>$ Choice of media like visual/auditory/reading/ discussion groups or individual work can be recommended.

$>$ Learning strategies can be recommended.

$>$ Students can be recommended certain student groups to work with based on the same intelligences in the beginning and later on the groups could be reshuffled with a mix of intelligences for better exposure and learning.

$>$ The initial recommendations can be cross checked by monitoring students' performance after they follow the recommended guidelines.

$>$ A work plan can be devised to polish less dominant intelligences.

$>$ Double loop learning can be planned if single loop does not result in fruitful outcomes.

Based on this theoretical work, it can be concluded that MMLA with the help of latest advancements in technology can capture and analyze the variations or a blend of intelligences at work in a student's learning process, enabling him/her excel in a particular mode of learning. However, data should be used appropriately, sensitively and with consent keeping in mind the ethical considerations (MacNeill, Campbell, \& Hawksey, 2014). Technology has great potential and that time is not far away when, with the help of educationists, the best practices in online educational design will make it attain a level that would surpass face-to-face education. In any case, MMLA should build a very strong connection with learning sciences to achieve a pedagogic design which can capture cognition, metacognition and intelligences patterns.

\section{CONCLUSION}

While looking for the potential of MMLA to trace multiple intelligences, the paper has attempted to establish the significance of the MI theory for online education. Therefore, it can be concluded that online education is multimodal as it has the potential to encompass multiple intelligences. Continuous researches on the use of latest technologies for transforming learning theory into praxis can make online education more student friendly with the help of MMLA. The study calls for future empirical/action researches in this area about the relationship of multiple intelligences, online education and multimodal learning analytics as well as the possibility of technology to support learning theory, styles and teaching methods and strategies. More studies on how MMLA can facilitate MOOCS, open education and mobile learning should also take place. 


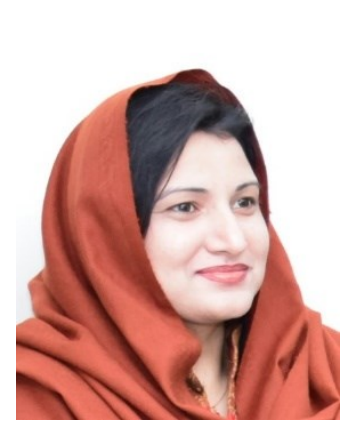

Ayesha PERVEen is an Assistant Professor of English Language and Literature \& Head, Department of Social Sciences and Humanities at Virtual University of Pakistan. She has more than 15 years of experience of teaching English language and literature in face to face and online modes. Her educational interests include adapting established educational theories for open and distance learning or creating new ones in view of the existing challenges. She is an interdisciplinary researcher and her research interests include open and distance learning, blended learning, learning analytics, critical theory, critical discourse analysis, critical pedagogy, English language teaching and literatures written in English. She is also the co-editor of Virtual University hosted Journal of Distance Education and Research (JDER). She has 7 journal articles published in international indexes and 1 international book chapter (accepted), many national articles, editorials and conference papers to her credit.

\section{Ayesha PERVEen}

Department of English, Faculty of Arts

Virtual University of Pakistan, 54000, Lahore, Pakistan

Phone: +92 99201505 / 8511

E-mail: ayesha@vu.edu.pk

\section{REFERENCES}

Armstrong, T. (2009). Multiple intelligences in the classroom. Alexandria, Virginia: Association for Supervision and Curriculum Development (ASCD).

Arnold, K. E., \& Pistilli, M. D. (2012, April). Course signals at Purdue: Using learning analytics to increase student success. In Proceedings of the 2nd International Conference on Learning Analytics and Knowledge (pp. 267-270). ACM.

Baker, R. S., \& Inventado, P. S. (2014). Educational data mining and learning analytics. In Learning Analytics (pp. 61-75). Springer: New York.

Blikstein, P. (2013, April). Multimodal learning analytics. In Proceedings of the third international conference on learning analytics and knowledge (pp. 102-106). ACM.

Blikstein, P., \& Worsley, M. (2016). Multimodal learning analytics and education data mining: Using computational technologies to measure complex learning tasks. Journal of Learning Analytics, 3(2), 220-238. http://dx.doi.org/10.18608/jla.2016.32.11.

Barrington, E. (2004). Teaching to student diversity in higher education: how Multiple Intelligence Theory can help. Teaching in Higher Education, 9 (4), 421-434. http://dx.doi.org/10.1080/1356251042000252363

Campbell, L., Campbell, B., \& Dickinson, D. (1999). Through multiple intelligences. Needham Heights, MA: Allyn \& Bacon.

Campbell, J. \& Oblinger, D. (2007). Academic Analytics. EDUCAUSE Quarterly. October (2007).

Chatti, M. A., Dyckhoff, A. L., Schroeder, U., \& Thus, H. (2012). A reference model for learning analytics. International Journal of Technology Enhanced Learning, 4(5-6), 318331. http://dx.doi.org/10.1504/IJTEL.2012.051815

Clow, D. (2012, April). The learning analytics cycle: closing the loop effectively. In Proceedings of the 2nd international conference on learning analytics and knowledge (pp. 134138). ACM.

Cooper, A. (2012). What is analytics? Definition and essential characteristics. Cetis Analytics Series, 1(5).Retrieved from http://citeseerx.ist.psu.edu 
Dawson, S., \& Siemens, G. (2014). Analytics to literacies: The development of a learning analytics framework for multiliteracies assessment. The International Review of Research in Open and Distributed Learning, 15(4). http://dx.doi.org/10.19173/irrodl.v15i4.1878

Duval, E. (2011, February). Attention please!: learning analytics for visualization and recommendation. In Proceedings of the 1st International Conference on Learning Analytics and Knowledge (pp. 9-17). ACM.

De Liddo, A., Shum, S. B., Quinto, I., Bachler, M., \& Cannavacciuolo, L. (2011, February). Discourse-centric learning analytics. In Proceedings of the 1st International Conference on Learning Analytics and Knowledge (pp. 23-33). ACM.

Ferguson, R. (2012). Learning analytics; drivers, developments and challenges. International Journal of Technology Enhanced Learning, 4(5-6), 304-317. doi: 10.1504/IJTEL.2012.051816

Gardner, H. (2011). Frames of mind: The theory of multiple intelligences. New York: Basic books.

Gasevic, D., Dawson, S., \& Siemens, G. (2015). Let's not forget: Learning analytics are about learning. TechTrends, 59(1), 64-71. doi:10.1007/s11528-014-0822-x

Greller, W., \& Drachsler, H. (2012). Translating learning into numbers: A generic framework for learning analytics. Journal of Educational Technology \& Society, 15(3), 42-57. Retrieved from http://ifets.info/journals/15_3/4.pdf

Healion, D., Russell, S., Cukurova, M., \& Spikol, D. (2017, March). Tracing physical movement during practice-based learning through multimodal learning analytics. In LAK (pp. 588-589).

Klemencic, M., \& Chirikov, I. (2015). How Do We Know How Students Experience Higher Education? On the Use of Student Surveys. In The European Higher Education Area (pp. 361-379). Springer International Publishing. Retrieved from https: //link.springer.com/chapter/10.1007/978-3-319-20877-0_24

Lias, T. E., \& Elias, T. (2011). Learning Analytics: The Definitions, the Processes, and the Potential. http:// learninganalytics.net/LearningAnalyticsDefinitions ProcessesPotential.pdf

Lockyer, L., Heathcote, E., \& Dawson, S. (2013). Informing pedagogical action: Aligning learning analytics with learning design. American Behavioral Scientist, 57(10), pp 1439-1459. doi: 10.1177/0002764213479367.

MacNeill, S. (2012). Analytics: What is changing and why does it matter. Cetis Analytics Series, 1(1). Retrieved from http://publications.cetis.org.uk/2012/511

MacNeill, S., Campbell, L. M., \& Hawksey, M. (2014). Analytics for Education. Reusing Open Resources: Learning in Open Networks for Work, Life and Education, 154. Routledge.

Mazzola, L., \& Mazza, R. (2011, March). Visualizing learner models through data aggregation: a test case. In Proceedings of the red-conference, rethinking education in the knowledge society (pp. 372-380).

Medeiros Vieira, L. M., Ferasso, M., \& Schroeder, C. D. S. (2014). Connecting Multiple Intelligences through Open and Distance Learning: Going Towards a Collective Intelligence? European Journal of Open, Distance and E-Learning, 17(1), 108-117. Retrieved from http: //www.eurodl.org/index.php?p= archives\&sp=brief\&article $=614$

Morency, L. P., Oviatt, S., Scherer, S., Weibel, N., \& Worsley, M. (2013, December). ICMI 2013 grand challenge workshop on multimodal learning analytics. In Proceedings of the 15th ACM on International conference on multimodal interaction (pp. 373-378). ACM.

Munoz-Cristobal, J. A., Rodriguez Triana, M., Bote-Lorenzo, M. L., Villagra-Sobrino, S. L., AsensioPerez, J. I., \& Martínez-Mones, A. (2017). Toward Multimodal Analytics in Ubiquitous Learning Environments. In Joint Proceedings of the Sixth Multimodal Learning Analytics (MMLA) Workshop and the Second Cross-LAK Workshop co-located with 7th International Learning Analytics and Knowledge Conference (Vol. 1828, No. EPFL-CONF-229374, pp. 6067). CEUR. 
Nolen, J. L. (2003). Multiple intelligences in the classroom. Education, 124(1), 115-119. Retrieved from http://connection.ebscohost.com/c/articles/11047099/multipleintelligences-classroom

Ochoa, X., Chiluiza, K., Mendez, G., Luzardo, G., Guaman, B., \& Castells, J. (2013, December). Expertise estimation based on simple multimodal features. In Proceedings of the 15th ACM on International conference on multimodal interaction (pp. 583-590). ACM.

Powell, S., \& MacNeill, S. (2012). Institutional readiness for analytics. Cetis Analytics Series, 1(8). Retrieved from http://publications.cetis.org.uk/2012/527

Riha, M., \& Robles-Pina, R. A. (2009). The influence of multiple intelligence theory on webbased learning. MERLOT Journal of Online Learning and Teaching, 5(1), 97-103. Retrieved from http://jolt.merlot.org/vol5no1/robles-pina_0309.htm

Siemens, G. (2012, April). Learning analytics: envisioning a research discipline and a domain of practice. In Proceedings of the 2nd International Conference on Learning Analytics and Knowledge (pp. 4-8). ACM.

Siemens, G., \& Long, P. (2011). Penetrating the Fog: Analytics in Learning and Education. EDUCAUSE review, 46(5), 30. Retrieved from http://er.educause.edu/articles/ 2011/9/penetrating-the-fog-analytics-in-learning-and-education

Siemens, G. (2012, April). Learning analytics: envisioning a research discipline and a domain of practice. In Proceedings of the 2nd International Conference on Learning Analytics and Knowledge (pp. 4-8). ACM.

Siemens, G., \& d Baker, R. S. (2012, April). Learning analytics and educational data mining: towards communication and collaboration. In Proceedings of the 2nd international conference on learning analytics and knowledge (pp. 252-254). ACM.

Shum, S. B., \& Crick, R. D. (2012, April). Learning dispositions and transferable competencies: pedagogy, modelling and learning analytics. In Proceedings of the 2nd International Conference on Learning Analytics and Knowledge (pp. 92-101). ACM.

Shum, S. B., \& Ferguson, R. (2012). Social learning analytics. Journal of Educational Technology \& Society, 15(3), 3-26. Retrieved from http://www.ifets.info/journals/15_3/2.pdf

Siemens, G. (2013). Learning analytics: The emergence of a discipline. American Behavioral Scientist, 57 (10). doi:10.1177/0002764213498851

Smith, M. K. (2002). Howard Gardner and multiple intelligences. The encyclopedia of informal education, 15, 2012.

Worsley, M. (2012, October). Multimodal learning analytics: enabling the future of learning through multimodal data analysis and interfaces. In Proceedings of the 14th ACM international conference on Multimodal interaction (pp. 353-356). ACM.

Worsley, M., \& Blikstein, P. (2013, April). Towards the development of multimodal action based assessment. In Proceedings of the third international conference on learning analytics and knowledge (pp. 94-101). ACM.

Worsley, M., \& Blikstein, P. (2014, July). Using Multimodal Learning Analytics to Study Learning Mechanisms. In Educational Data Mining 2014. doi:10.1007/s10758-0149223-7 